Proc. Indian Acad. Sci. (Earth Planet. Sci.), Vol. 95, No. 2, July 1986, pp. 153-167.

(C) Printed in India.

\title{
Numerical hysteresis model for intermittent studies in unsaturated soils
}

\author{
M BANERJEE \\ Department of Geophysics, Banaras Hindu University, Varanasi 221005 , India \\ MS received 4 March 1983; revised 1 October 1985
}

\begin{abstract}
In the present study, the use of one of the recent dependent domain models of capillary hysteresis in the numerical analysis of intermittent infiltration and redistribution of water in two types of soils (a sand and Rubicon Sandy Loam) has been shown. The numerical results for both the soils have been presented in terms of pressure head depth, moisture content depth and the pressure head-moisture content relationships. The capillary hysteresis model has been found to be very useful for the prediction of both wetting and drying scanning curves of various orders.
\end{abstract}

Keywords. Capillary hysteresis model; unsaturated soils; scanning curves; intermittent conditions.

\section{Introduction}

In ground water recharge problems, the study of soil moisture-depth profile under rapid intermittent surface flux conditions requires the inclusion of a capillary hysteresis model in the numerical simulation of flow processes. Under intermittent conditions, the effect of hysteresis is very significant and therefore it is a priori necessary to have the complete knowledge of higher order wetting and drying scanning curves. Watson and Perrens (1973) developed an interpolative capillary hysteresis model for the evaluation of higher order scanning curves from experimentally measured primary scanning curves of soil-moisture. The method is limited in application since it is quite impossible to measure all the scanning curves (Everett 1967) in the laboratory. In this regard, the conceptually based physical models are quite suitable for prediction of scanning curves from a limited set of experimental data.

Among the conceptually based domain models, Mualem and Dagan (1975) developed a dependent domain model by accommodating the concept of dependency of the state of neighbouring pores (Everett 1967; Topp 1971b) in the independent domain model of Mualem (1974) by including parameters like blockage against air-entry, $P_{d}(\theta)$, and blockage against water-entry, $P_{w}(\theta)$. Mualem (1977) presented a model to evaluate the hysteresis curve from either the boundary drying or the boundary wetting curve. Parlange (1976) proposed a simple ex trapolative conceptual domain model of capillary hysteresis using the Mualem diagram. The model requires only the knowledge of the boundary loop and its derivative to predict all primary and other higher order wetting and drying scanning curves.

The use of the non-independent domain model of Poulovassilis and Childs (1971) in the numerical analysis of intermittent flow study is shown by Lees and Watson (1975).

A list of symbols is given at the end of the paper. 
The purpose of the present study is to show the use of the dependent domain model of Mualem and Dagan (1975) in the numerical study of intermittent infiltration and redistribution of water in two types of soil. The types of soil selected are a sand and Rubicon Sandy Loam which are subject to the assumptions that the medium is homogeneous, isotropic, isothermal and rigid in behaviour. It is also shown that, in the subsequent cycles of intermittent sequences of flow processes, how the necessary higher order scanning curves are evolved for the surface node.

\section{Numerical method}

The water transport equation for unsaturated soil may be written as

$$
C(h) \frac{\partial h}{\partial t}=\frac{\partial}{\partial Z}\left[K(h) \frac{\partial h}{\partial Z}\right]+\frac{\partial K}{\partial Z}(h),
$$

where $C$ is the specific moisture capacity, $h$ the pressure head and $Z$ the depth with positive direction upwards, $t$ the time, and $K$ the unsaturated hydraulic conductivity.

The numerical solution of the above equation can be obtained by a finite difference technique following Crank-Nicholson's approach. The method involves the use of a three-point central difference grid (figure 1) with the current value being evaluated at the mid-point. The finite difference form of the (1) is given by

$$
A_{j} h_{(j-1, k+1)}+B_{j} h_{(j, k+1)}+C_{j} h_{(j+1, k+1)}=D_{j} ; \quad(1 \leqslant j \leqslant N)
$$

where the equation coefficients $A_{j}, B_{j}, C_{j}$ and $D_{j}$ are given by

$$
\begin{aligned}
& A_{j}=-K_{\left(j-\frac{1}{2}, k+\frac{1}{2}\right),} \\
& B_{j}=\frac{2}{r} C_{\left(j, k+\frac{1}{2}\right)}-A_{j}-C_{j},
\end{aligned}
$$

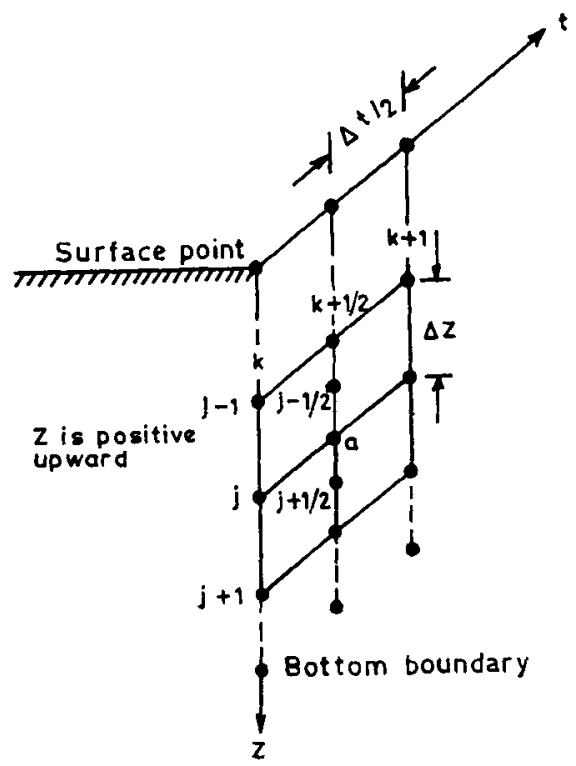

Figure 1. Finite difference grid setting. 


$$
\begin{aligned}
C_{j}= & K_{\left(j+\frac{1}{2}, k+\frac{1}{2}\right)}, \\
D_{j}= & A_{j}\left[h_{(j, k)}-h_{(j-1, k)}\right]+C_{j}\left[h_{(j, k}-h_{(j+1, k)}\right] \\
& +2 \Delta Z\left(A_{j}-C_{j}\right)+2 C_{\left(j, k+\frac{1}{2}\right)}\left[h_{(j, k)} / r\right],
\end{aligned}
$$

where

$$
r=\Delta t / \Delta Z^{2} \text {. }
$$

Equation (2) represents a set of $N$ linear equations for $N$ nodes along the depth axis which is given by

$$
\begin{aligned}
& A_{1} h_{0}+B_{1} h_{1}+C_{1} h_{2}=D_{1} \\
& A_{2} h_{1}+B_{2} h_{2}+C_{2} h_{3} \quad=D_{2} \\
& A_{3} h_{1}+B_{3} h_{2}+C_{3} h_{3} \quad=D_{3} \\
& A_{N} h_{N-1}+B_{N} h_{N}+C_{N} h_{N+1}=D_{N}
\end{aligned}
$$

The matrix obtained in (8) is known as the 'tridiagonal matrix'.

To facilitate the solution of (3) through (7), the 'auto-selection iteration technique' was employed in a computer program developed following the approach elaborated by Whisler and Watson (1968). In (1), the $K(h)$ relationship is hysteretic, it was desirable to obtain the capillary conductivity values, from a $K(\theta)$ relationship. The specific moisture capacity was obtained by taking a gradient along the hysteretic path of a particular node at a desired pressure head value from a $h(\theta)$ relationship. Moreover the $C(h)$ curve is very unstable and oscillatory in nature and becomes discontinuous on the boundary drying curve within the air-entry region. To avoid these difficulties it is assumed that $\mathrm{d} \theta / \mathrm{d} h$ should be constant within a $\Delta h=\left(h_{i}-h_{i-1}\right)$ interval, but in doing so the resulting $C(h)$ histogram becomes discontinuous between successive $h$ intervals. So, as a remedy the average $C(h)$ values were obtained in adjacent intervals and then interpolated at the required point. At no time should the $C(h)$ value be negative or zero. It should have always a finite positive value.

\subsection{Mualem-Dagan model of capillary hysteresis}

It is sufficient for continuity of discussion at this point to outline the general form of the equations.

2.1a Entry into the scanning curve system from the boundary wetting curve: The equation for drying scanning curve is given as:

$$
\begin{aligned}
\theta\left[\begin{array}{cc}
\psi_{1} & \psi_{N} \\
\psi_{\min } \psi_{2}--- & \psi
\end{array}\right]= & \theta_{w}\left(\psi_{1}\right)-\bar{P}_{d}(\theta) \cdot[1-H(\psi)] \cdot\left[L\left(\psi_{N}\right)-L(\psi)\right] \\
& +\sum_{j=1}^{(N-1) / 2} \bar{P}_{d}\left(\theta_{2 j}\right) \cdot\left[1-H\left(\psi_{2 j}\right)\right] \cdot\left[L\left(\psi_{2 j+1}\right)-L\left(\psi_{2 j-1}\right)\right] .
\end{aligned}
$$


In the above equation $N$ should be odd and $\geqslant 1$.

The equation for wetting scanning curves is given as:

$$
\begin{aligned}
\theta\left[\begin{array}{cc}
\psi_{1} & \psi \\
\psi_{\min } \psi_{2}--\psi_{N}
\end{array}\right]= & \theta_{w}\left(\psi_{1}\right)+\bar{P}_{d}\left(\theta_{N}\right) \cdot\left[\left(1-H\left(\psi_{N}\right)\right] \cdot\left[L(\psi)-L\left(\psi_{N}\right)\right]\right. \\
& -\sum_{j=1}^{N / 2} \bar{P}_{d}\left(\theta_{2 j}\right) \cdot\left[1-H\left(\psi_{2 j}\right)\right] \cdot\left[L\left(\psi_{2 j-1}\right)-L\left(\psi_{2 j}\right)\right] \\
& +\sum_{j=1}^{(N / 2)-1} \bar{P}_{d}\left(\theta_{2 j}\right) \cdot\left[1-H\left(\psi_{2 j}\right)\right] \cdot\left[L\left(\psi_{2 j+1}\right)-L\left(\psi_{2 j-1}\right)\right] .
\end{aligned}
$$

In (10) $N$ should be even and $\geqslant 2$.

2.1b Entry into the scanning curve system from the boundary draining curve: The equation for the drying scanning curve is written as:

$$
\begin{aligned}
\theta\left[\begin{array}{cc}
\psi_{\max } \psi_{2} \ldots \psi_{N} \\
\psi_{1}
\end{array}\right]= & \theta_{d}\left(\psi_{1}\right)-\bar{P}_{d}(\theta) \cdot[1-H(\psi)] \cdot\left[L\left(\psi_{N}\right)-L(\psi)\right] \\
& +\sum_{j=1}^{N / 2} \bar{P}_{d}\left(\theta_{2 j-1}\right) \cdot\left[1-H\left(\psi_{2 j-1}\right)\right] \\
& \times\left[L\left(\psi_{2 j}\right)-L\left(\psi_{2 j-1}\right)\right] \\
& -\sum_{j=1}^{(N / 2)-1} \bar{P}_{d}\left(\theta_{2 j+1}\right) \cdot\left[1-H\left(\psi_{2 j+1}\right)\right] \\
& {\left[L\left(\psi_{2 j}\right)-L\left(\psi_{2 j+1}\right)\right] . }
\end{aligned}
$$

In (11) $N$ should be even and $\geqslant 2$.

The equation for the wetting scanning curve is given as:

$$
\begin{aligned}
\theta\left[\begin{array}{c}
\psi_{\max } \psi_{2} \\
\psi_{1}
\end{array}\right]= & \theta_{d}\left(\psi_{1}\right)+\bar{P}_{d}\left(\theta_{N}\right) \cdot\left[1-H\left(\psi_{N}\right)\right] \cdot\left[L(\psi)-L\left(\psi_{N}\right)\right] \\
& +\sum_{j=1}^{(N-1) / 2} \bar{P}_{d}\left(\theta_{2 j-1}\right) \cdot\left[1-H\left(\psi_{2 j-1}\right)\right] \cdot\left[L\left(\psi_{2 j}\right)-L\left(\psi_{2 j-1}\right)\right] \\
& -\sum_{j=1}^{(N-1) / 2} \bar{P}_{d}\left(\theta_{2 j+1}\right) \cdot\left[1-H\left(\psi_{2 j+1}\right)\right] \cdot\left[L\left(\psi_{2 j}\right)-L\left(\psi_{2 j+1}\right)\right]
\end{aligned}
$$

In (12) $N$ should be odd and $\geqslant 1$.

\subsection{Description of the physical system}

The porous materials selected for the present study are a sand (data obtained from Perrens and Watson 1977, who called it no. 17 sand) and Rubicon Sandy Loam (from Topp 1969). At a saturated moisture content of $0.292 \mathrm{~cm}^{3} / \mathrm{cm}^{3}$, No. 17 sand has a capillary conductivity of $0.8 \mathrm{~cm} / \mathrm{min}$ and an air-entry value (Childs 1960 ) of $-34.5 \mathrm{~cm}$. 

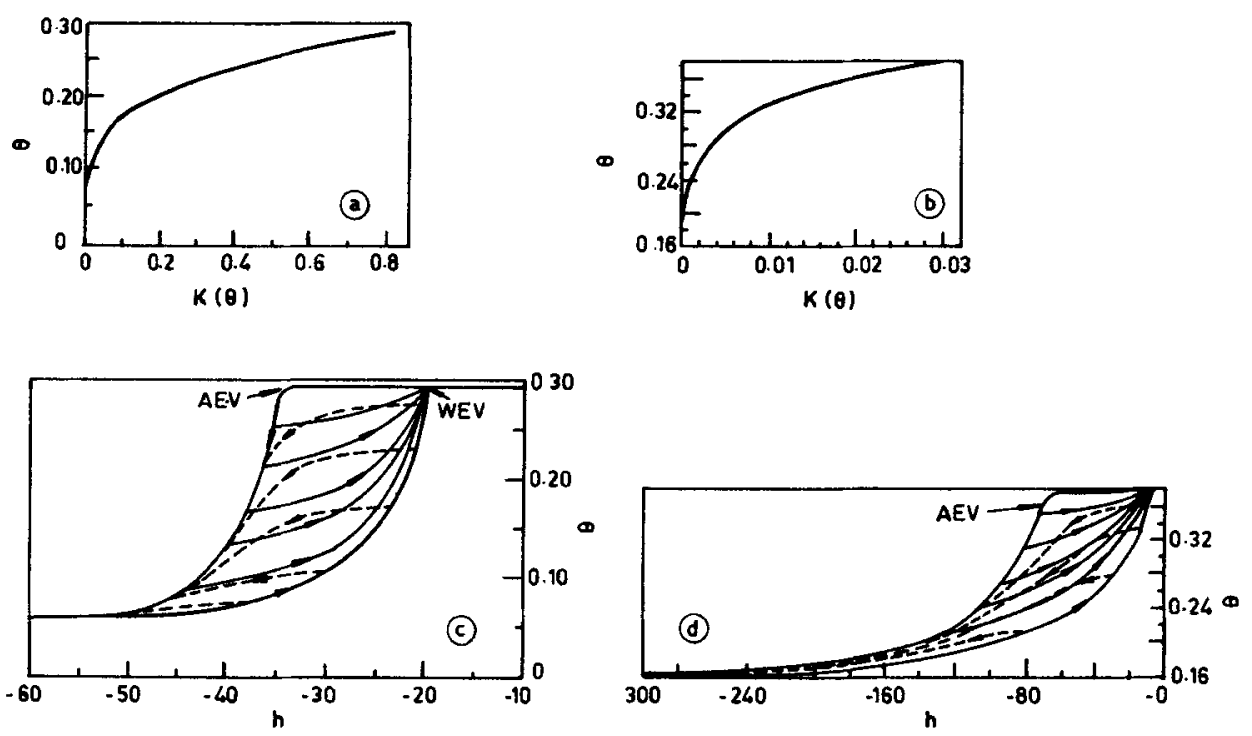

Figure 2. The hydrologic characteristics of the porous media. a. $K(\theta)$ for sand, b. $K(\theta)$ for sand, c. $h(\theta)$ for Rubicon Sandy Loam, and d. $h(\theta)$ for Rubicon Sandy Loam.

Similarly Rubicon Sandy Loam has a capillary conductivity of $0.03 \mathrm{~cm} / \mathrm{min}$ at a saturated moisture content of $0.38 \mathrm{~cm}^{3} / \mathrm{cm}^{3}$ with an air-entry value of $-30.0 \mathrm{~cm}$.

The analysis presented is the unsteady flow to a semi-infinite and initially uniformly dry profile for a $70.0 \mathrm{~cm}$ column of No. 17 sand, whereas for the Rubicon Sandy Loam a water table was set at a depth of $120 \mathrm{~cm}$ below the surface of an initially partially dry profile. In each case the entire column was divided into equal intervals in the vertical $Z$ direction with each node separated by 1 and $1.2 \mathrm{~cm}$ for No. 17 sand and Rubicon Sandy Loam respectively. This yields 71 nodes for the sand and 101 nodes for Sandy Loam. The hydrologic characteristics $K(\theta)$ and $h(\theta)$ for the sand and Rubicon Sandy Loam are shown in figures $2 \mathrm{a}$ and $\mathrm{b}$ (Watson and Perrens 1973) and figures $2 \mathrm{c}$ and $\mathrm{d}$ (Topp 1969).

\subsection{Evaluation of the domain functions}

A capillary hysteresis subprogram has been developed which is based on the domain model of Mualem and Dagan (1975). This subprogram generates the various primary, secondary and other higher order redrying and rewetting scanning curves. To effect this a separate subroutine is used for the evaluation of distribution functions $H(h), P_{d}(\theta)$ and $L(h)$ for both sand and Rubicon Sandy Loam. For the evaluation of these functions apart from the boundary loop, one primary drying curve for each soil originating from $\left(, h_{d}=-20.2 \mathrm{~cm} ;, \theta_{d}=0.27 \mathrm{~cm}^{3} / \mathrm{cm}^{3}\right)$ for the sand and $\left(, h_{d}=-6.0 \mathrm{~cm} ;, \theta_{d}\right.$ $=0.36 \mathrm{~cm}^{3} / \mathrm{cm}^{3}$ ) for the Rubicon Sandy Loam are also selected. In addition the distribution function $P_{w}(\theta)$ is also derived for Rubicon Sandy Loam using one primary wetting curve originating from $\left(h_{w}=-141.23 \mathrm{~cm} ; \theta_{w}=0.20 \mathrm{~cm}^{3} / \mathrm{cm}^{3}\right)$. The distribution functions $H(h), P_{d}(\theta)$ and $P_{w}(\theta)$ are shown in figures 3 through 6 . The subsequent predictions of various order of scanning curves during the solution process are made by these functions. 


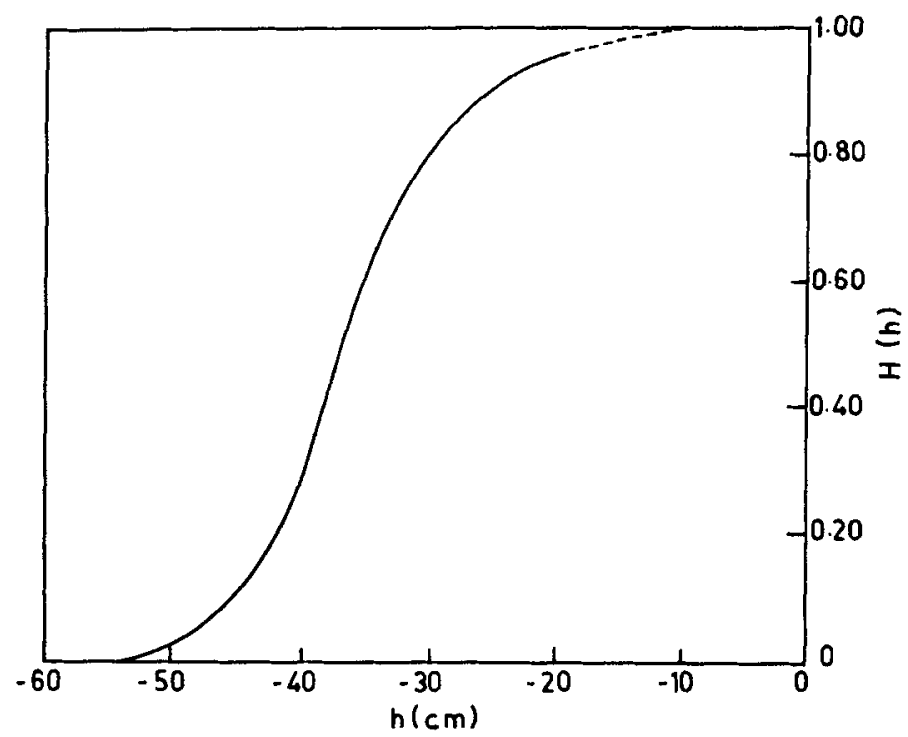

Figure 3. The distribution function, $H(h)$, for sand.

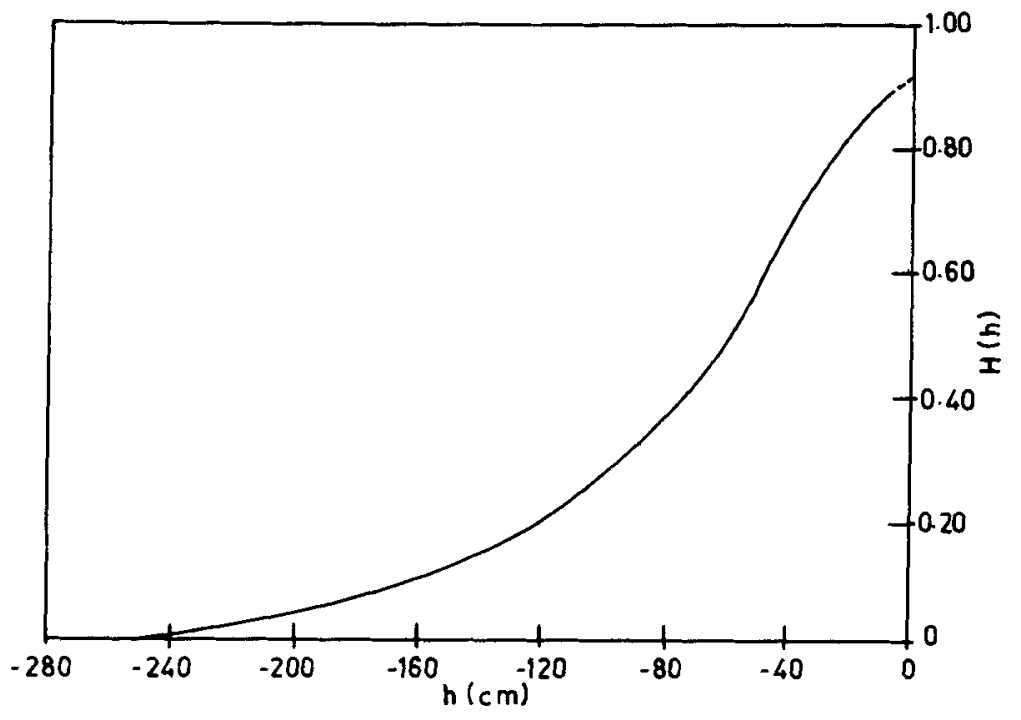

Figure 4. The distribution function, $H(h)$, for Rubicon Sandy Loam.

\subsection{Flux pattern}

2.4a Sand: In the case of sand, the surface flux $\left(F_{s}\right)$ applied and the time of change of boundary conditions constrained during the $4 \frac{1}{2}$ cycles of intermittence are as follows:

$$
\begin{aligned}
& F_{\mathrm{s}}=-0.5 \mathrm{~cm} / \mathrm{min} \text {, } \\
& F_{\mathrm{a}}=0 \text {, } \\
& 0 \leqslant t \leqslant 10 \mathrm{~min} \text {, } \\
& 10 \mathrm{~min} \leqslant t \leqslant 20 \mathrm{~min} \text {, } \\
& Z=0 \\
& Z=0 \text {. } \\
& F_{s}=-0.5 \mathrm{~cm} / \mathrm{min} \text {, } \\
& 20 \min \leqslant t \leqslant 21 \mathrm{~min}, \quad Z=0 \text {. }
\end{aligned}
$$




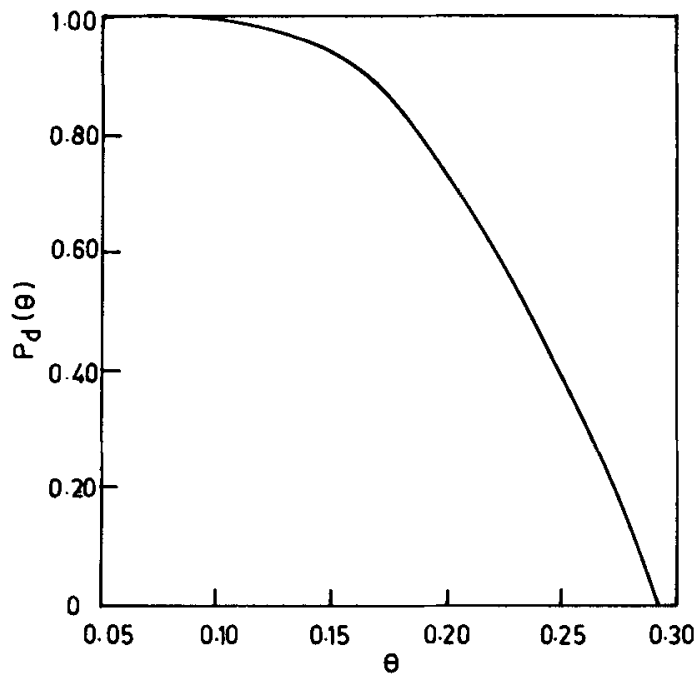

Figure 5. The function for pore blockage against air-entry, $P_{d}(\theta)$, for sand.

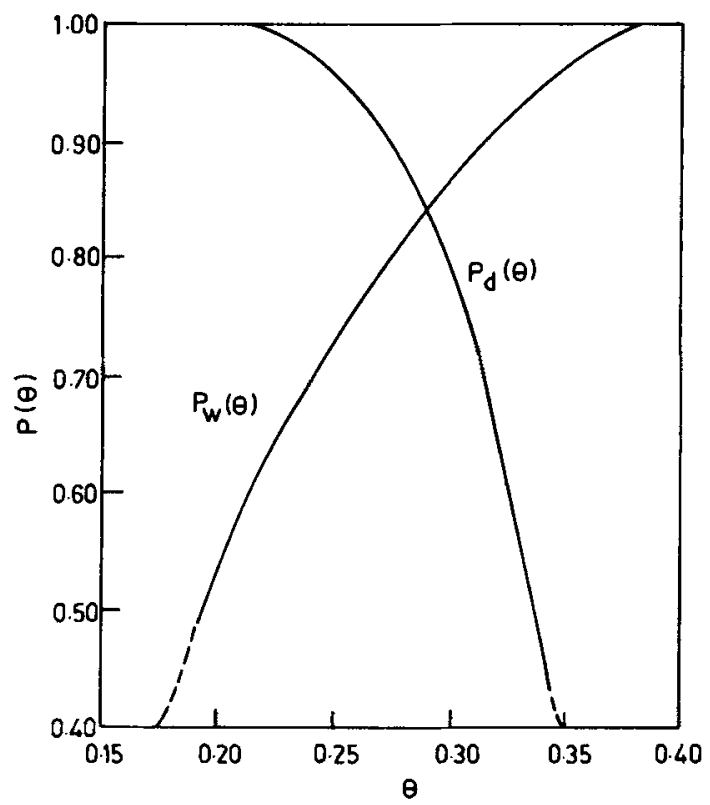

Figure 6. The function for pore blockage against air-entry, $P_{d}(\theta)$, and water-entry, $P_{w}(\theta)$, for Rubicon Sandy Loam.

$F_{1}=0$,

$21 \min \leqslant t \leqslant 25 \min , \quad Z=0$.

$F_{\mathrm{a}}=-0.5 \mathrm{~cm} / \mathrm{min}$,

$25 \mathrm{~min} \leqslant t \leqslant 25 \cdot 3 \mathrm{~min}$

$Z=\mathbf{0}$.

$F_{s}=0$, $25.3 \mathrm{~min} \leqslant t \leqslant 26.3 \mathrm{~min}$

$F_{\mathrm{z}}=-0.5 \mathrm{~cm} / \mathrm{min}$ $26.3 \min \leqslant t \leqslant 26.4 \mathrm{~min}$,

$F_{s}=0$, $26.4 \mathrm{~min} \leqslant t \leqslant 26.7 \mathrm{~min}$,

$F_{1}=-0.5 \mathrm{~cm} / \mathrm{min}$, $26.7 \mathrm{~min} \leqslant t \leqslant 36.7 \mathrm{~min}$,

$Z=0$.

$Z=0$.

$Z=0$.

$\boldsymbol{Z}=\mathbf{0}$. 
2.4b Rubicon Sandy Loam: The surface flux applied during the $2 \frac{1}{2}$ cycles of intermittence in Rubicon Sandy Loam is:

$$
\begin{aligned}
& F_{2}=-0.02 \mathrm{~cm} / \mathrm{min}, \\
& F_{1}=0, \\
& F_{3}=-0.015 \mathrm{~cm} / \mathrm{min}, \\
& F_{1}=0, \\
& F_{3}=-0.02 \mathrm{~cm} / \mathrm{min},
\end{aligned}
$$

$$
\begin{gathered}
0 \quad \leqslant t \leqslant 100 \mathrm{~min}, \\
100 \mathrm{~min} \leqslant t \leqslant 200 \mathrm{~min}, \\
200 \mathrm{~min} \leqslant t \leqslant 250 \mathrm{~min}, \\
250 \mathrm{~min} \leqslant t \leqslant 300 \mathrm{~min}, \\
300 \mathrm{~min} \leqslant t \leqslant 350 \mathrm{~min},
\end{gathered}
$$

$$
\begin{aligned}
& Z=0 . \\
& Z=0 . \\
& Z=0 . \\
& Z=0 . \\
& Z=0 .
\end{aligned}
$$

\section{Numerical results and discussions}

\subsection{Sand}

The numerical results for pressure head-depth, moisture content-depth and pressure head-moisture content relationships have been presented in figures, 7, 8 and 9 , respectively. The numerals on figures 7 and 8 represent the infiltration profiles (the solid lines) at the end of $10 \mathrm{~min}$ (for the 1st cycle), $21 \mathrm{~min}$ ( $2 \mathrm{nd}$ cycle), 25.3 min (3rd cycle), $26.4 \mathrm{~min}$ (4th cycle) and $36.7 \mathrm{~min}$ ( $4 \frac{1}{2}$ cycles), and the redistribution profiles (the dashed lines) at the end of $20 \mathrm{~min}$ (for $1 \mathrm{st}$ cycle), $25 \mathrm{~min}$ ( $2 \mathrm{nd}$ cycle), $26.3 \mathrm{~min}$ ( $3 \mathrm{rd}$ cycle), 26.7 min (4th cycle) for both pressure head-depth and moisture content-depth relationships.

In the 1st cycle of intermittence, the 10 min pressure head and moisture content profiles in figures 7 and 8 show that during the 1 st infiltration event of 10 min the soil has got wet up to a depth of $-26.0 \mathrm{~cm}$ with an entry of $4.32 \mathrm{~cm}^{3}$ of water. The pressure head and moisture content were $-20.63 \mathrm{~cm}$ and $0.26 \mathrm{~cm}^{3} / \mathrm{cm}^{3}$, respectively. During the 10 min redistribution event of this cycle (see the $20 \mathrm{~min}$ profiles in figures 7 and 8 ), the soil drains under the influence of gravity and causes the near surface region to lose water. The draining water accumulates below the wet front to a depth of about $-40 \mathrm{~cm}$ (figure 8). At the end of this event the pressure head at the surface decreased to a value of $-42 \cdot 1 \mathrm{~cm}$ with moisture content as $0 \cdot 1 \mathrm{~cm}^{3} / \mathrm{cm}^{3}$.

It has been observed that during the redistribution event of the 1st cycle there is a development of negative moisture content gradient ( $d \theta / \mathrm{d} Z$ ) at $Z=0$ (figure 8). If $Z_{w f}$ is considered to be the wet front depth at the end of the 1st infiltration event, then it would be found that the reduced gradient $\left(\theta_{z}\right)$ will be negative on the draining part of the profile and zero near but above $Z_{w f}$. Below $Z_{w f}$ it develops a positive gradient, which shows that the drained water is accumulating below $Z_{w 5}$. At the maximum moisture content $\left(\theta_{m}\right)$ in the profile, $\mathrm{d} \theta / \mathrm{d} Z=0$. Further as $Z_{w f}$ increases, $\bar{\theta}_{z^{\prime}}$ decreases, the downward movement of water being greater. Also the redistribution rate is faster for a greater value of $Z_{w s}$.

The 21 and 25 min profiles for pressure head and moisture content are shown in figures 7 and 8, respectively, which developed during the infiltration and redistribution events of the 2 nd cycle of intermittence. The pressure head and moisture content values for the surface node during the infiltration event were $-21.6 \mathrm{~cm}$ and about $0.23 \mathrm{~cm}^{3} / \mathrm{cm}^{3}$, respectively, and those during the redistribution event were $-40.6 \mathrm{~cm}$ and $0.12 \mathrm{~cm}^{3} / \mathrm{cm}^{3}$. The total volume of water which entered the soil is $5.26 \mathrm{~cm}^{3}$. The depth to which the wet front reached during the infiltration and redistribution events are -40.0 and $-41.5 \mathrm{~cm}$, respectively (see figure 8 ). 


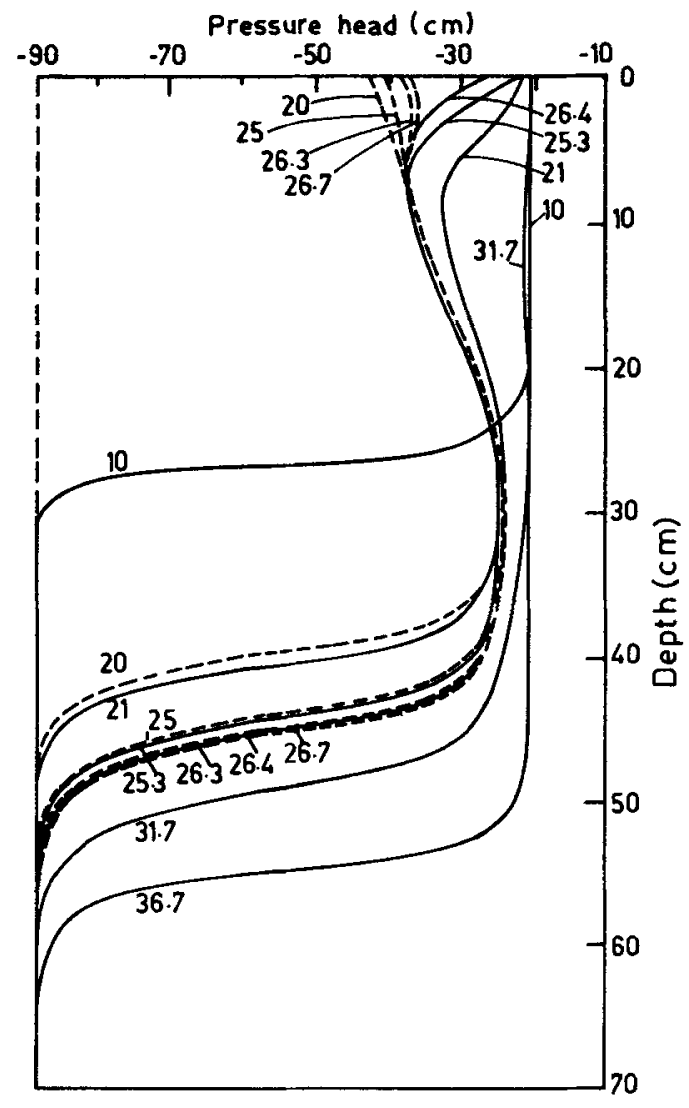

Figore 7. The pressure head depth profiles for $4 \frac{1}{2}$ cycles of intermittence in sand. Solid lines represent the infiltration and the broken lines the redistribution.

It has been found that during the $2 \mathrm{nd}$ cycle of intermittence the top $-10 \mathrm{~cm}$ of soil wets up quickly with positive moisture content gradient and it can be seen in the moisture depth profile of 21 min (figure 8) that a 'peak' forms around -10 and $30 \mathrm{~cm}$ of depth. The gradient $\left(\bar{\theta}_{z^{\prime}}\right)$ is sufficient to transmit the water below this peak. Further, a feature to be noted in the moisture depth profile of $25 \mathrm{~min}$ (figure 8) is that though the gradient $\left(\boldsymbol{\theta}_{z^{\prime}}\right)$ has become negative in the top few centimetres, yet below this depth the water drains along the 20 min profile, which is indicative of the fact that in sand the transmission zone is marked by this peak (see figure 8 ).

The pressure head and moisture content profiles of 25.3 and $26.3 \mathrm{~min}$, in figures 7 and 8 , developed during the infiltration and redistribution events of the 3 rd cycle of intermittence; and those developed during the infiltration and redistribution events of the 4 th cycle of intermittence are shown by the 26.4 and $26.7 \mathrm{~min}$ profiles also in figures 7 and 8 . The pressure head and moisture content values for the surface node during the infiltration event of the 4th cycle were $-26.4 \mathrm{~cm}$ and $0.17 \mathrm{~cm}^{3} / \mathrm{cm}^{3}$, respectively and those during the redistribution event were $-38.0 \mathrm{~cm}$ and $0.12 \mathrm{~cm}^{3} / \mathrm{cm}^{3}$. The depth to which the wet front moved down at the end of the 4 th cycle is $-46.0 \mathrm{~cm}$ (see $26.7 \mathrm{~min}$ profile in figure 8 ), and $5.6 \mathrm{~cm}^{3}$ of water had entered the soil column. The collation of 


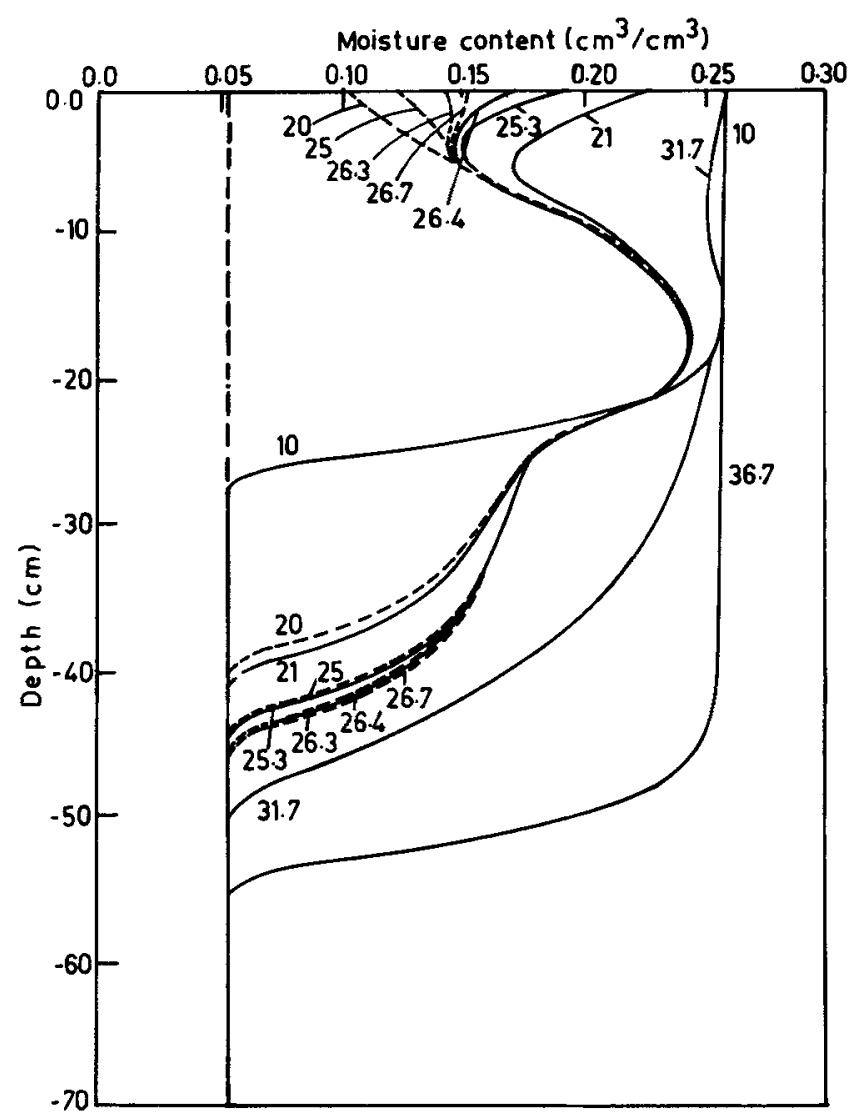

Figure 8. The moisture content-depth profiles for $4 \frac{1}{2}$ cycles of intermittence in sand. Solid lines represent the infiltration and the broken lines the distribution.

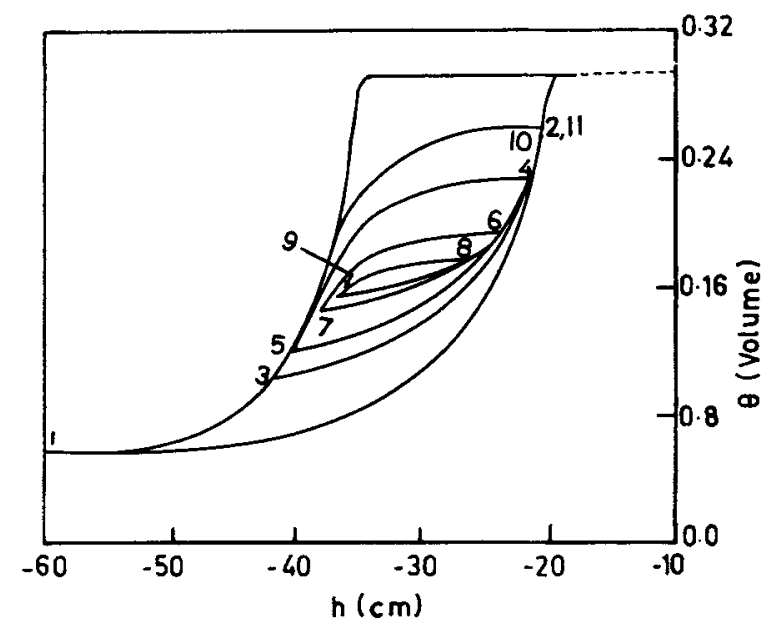

Figure 9. The $h(\theta)$ path of the surface node during the $4 \frac{1}{2}$ cycles of intermittence of sand. The numerals $1,2,3,-\ldots, 11$ correspond to cumulative times, $t=0,10,20,21,25,25 \cdot 3,26 \cdot 3,26 \cdot 4$, 26.7, 31.7 and $36.7 \mathrm{~min}$, respectively. 
the 26.3 and 26.7 min profiles of figure 8 indicates that during the 4 th cycle the peak still persists and remains in its position whereas the wet front moves down slowly.

In the final half cycle of intermittence, only the infiltration event has been considered. The 31.7 and 36.7 min profiles of this event in figures 7 and 8 show that the peak disappears with the development of a positive moisture content gradient. In fact, the 36.7 min profile is in equilibrium with constant pressure head and moisture content values, and water infiltrates under unit hydraulic gradient with a capillary conductivity value equal to the surface flux. The values of pressure head and moisture content at the end of this event were $-20.63 \mathrm{~cm}$ and $0.26 \mathrm{~cm}^{3} / \mathrm{cm}^{3}$, respectively. The wet front reached a depth of about $-56.0 \mathrm{~cm}$ with $7.65 \mathrm{~cm}^{3}$ of water entering the soil column.

Figure 9 shows the history of imbibition and drainage of the surface node after a number of intermittent infiltration and redistribution sequences. The numerals $1,2,3$, - - - , 9 correspond to the time $t=0,10,20,21,25,25 \cdot 3,26 \cdot 3,26.4$ and $26 \cdot 7 \mathrm{~min}$ respectively at which pressure head and moisture content reversals have occurred. It can be ascertained from figure 9 that upon continued infiltration during the final infiltration event the current quarternary rewetting scanning curve closes the inner and outer loops at points $8,6,4$, and 2 and advances to the points 10 and 11 which correspond to the times 31.7 and $36.7 \mathrm{~min}$ respectively. Moreover as the infiltration continues, the surface node remains at the point 11 and the bottom nodes start to come to equilibrium with the surface node. Thus the hysteresis model is quite efficient in generating the various order of scanning curves of either wetting or draining (figure 9).

\subsection{Rubicon Sandy Loam}

The model is also tested with Rubicon Sandy Loam for intermittent conditions. The flux applied at the surface of the soil column has always been less than the saturated value of hydraulic conductivity (see flux pattern). The numerical results for pressure head-depth, moisture content-depth and pressure head-moisture content relationships have been given in figures 10,11 and 12, respectively. The numerals on figures 10 and 11 represent the infiltration profiles (solid lines) at the end of $100 \mathrm{~min}$ (for 1st cycle), $250 \mathrm{~min}$ (2nd cycle) and $350 \mathrm{~min}\left(2 \frac{1}{2}\right.$ cycles), and the redistribution profiles (dashed lines) at the end of $200 \mathrm{~min}$ (for 1 st cycle) and $300 \mathrm{~min}$ ( $2 \mathrm{nd} \mathrm{cycle)} \mathrm{for} \mathrm{both} \mathrm{pressure} \mathrm{head-}$ depth and moisture content-depth relationships.

The zero time profiles in figures 10 and 11 are for the initial equilibrium state. In these figures the $100 \mathrm{~min}$ and $200 \mathrm{~min}$ profiles are those developed during the infiltration and redistribution events respectively, of the 1 st cycle of intermittence. During these events the changes in pressure head and moisture content profiles occurred to a depth of about $-50.0 \mathrm{~cm}$. The $200 \mathrm{~min}$ moisture content depth profile shows that the drained water has redistributed below the depth of $-27 \mathrm{~cm}$ (see figure 11).

In the second cycle of intermittence, the infiltration and redistribution were set for $50 \mathrm{~min}$ each. The pressure head profiles for this cycle have been shown by the $250 \mathrm{~min}$ for infiltration and $300 \mathrm{~min}$ for redistribution events (see figure 10); and corresponding moisture content profiles are shown in figure 11 . The 300 min moisture content profile shows that the redistribution is not so marked as in the case of the previous redistribution event (figure 11). The reason is that the soil has reached that range of pressure head where the water content change occurs very little.

The final cycle of intermittence comprises of an infiltration event only (see $350 \mathrm{~min}$ 


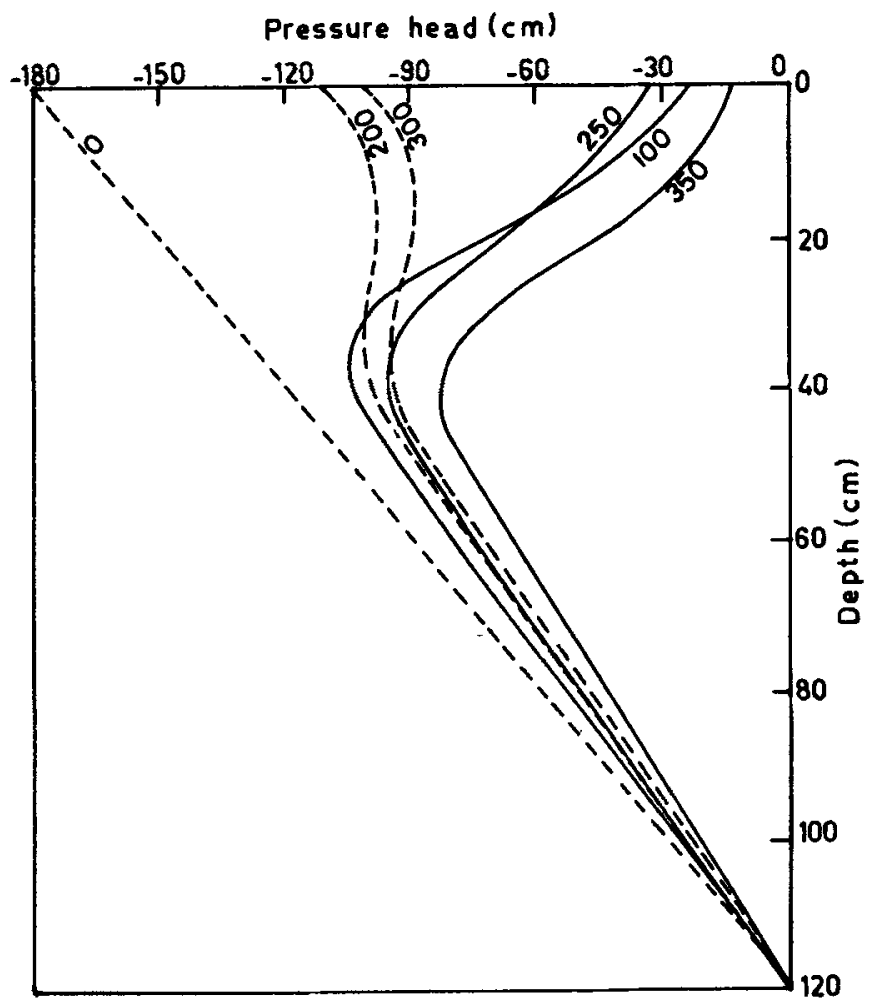

Figure 10. The $h(Z)$ profiles for 21 cycles of intermittence in Rubicon Sandy Loam. Solid lines represent the infiltration and the broken lines the redistribution.

profiles in figures 10 and 11 ), and during $50 \mathrm{~min}$ of infiltration the wetting has occurred mainly within $-46.0 \mathrm{~cm}$ of the soil. The pressure head and moisture content values for the surface node during each of the above mentioned events can be read from figures 10 and 11 .

In figure 12, the pressure head-moisture content relationship for the surface node is shown. The numerals $1,2,---, 5$ on the diagram correspond to the time $0,100,200,250$ and $300 \mathrm{~min}$, respectively, at which reversals have occurred. Upon continued infiltration the current rewetting curve (between 5 and 4 in figure 12) closes the tertiary (between 5 and 4 ) and secondary (between 3 and 2) loops at points 4 and 2 respectively, and advances beyond to the point 6 on the primary wetting curve (between 1 and 6 ) because the surface flux is greater now than during the initial infiltration.

Finally, it should be noted that for the prescribed surface flux and timings of the events, the steady state condition is not reached in Rubicon Sandy Loam.

\section{Conclusions}

The water movement in sand is found to be very rapid with the development of a distinct zone of transmission which is generally marked by a peak in moisture content 


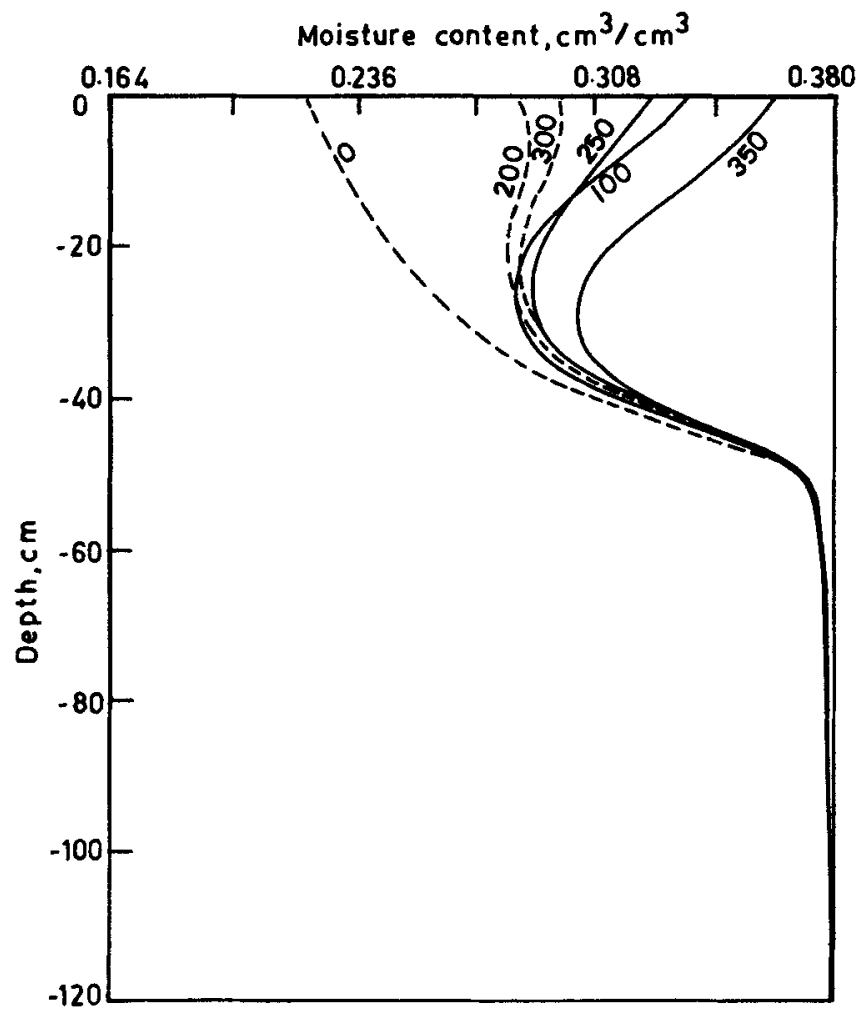

Figure 11. The $\theta(Z)$ profiles for $2 \frac{1}{2}$ cycles of intermittence in Rubicon Sandy Loam. Solid lines represent the infiltration and the broken lines the redistribution.

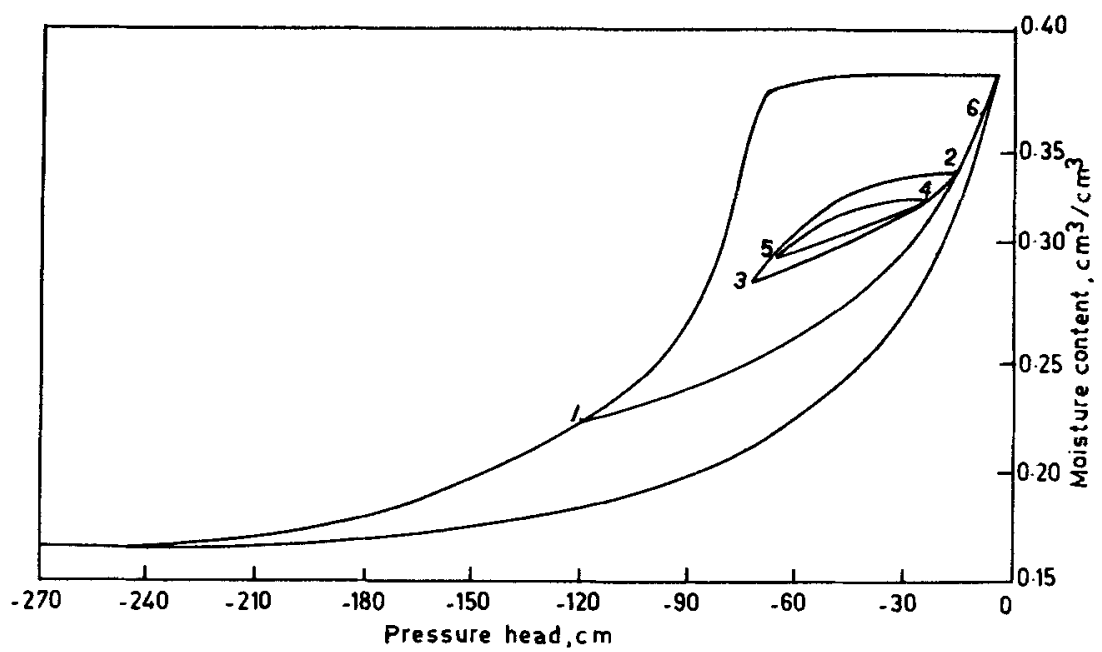

Figure 12. The $h(\theta)$ path of the surface node during the $2 \frac{1}{2}$ cycles of intermittence in Rubicon Sandy Loam. The numerals $1,2, \ldots, 6$ correspond to the cumulative time, $t=0,100,200$, 250,300 and $350 \mathrm{~min}$, respectively. 
profile. The peak, however, disappears when infiltration is continued for a longer period; whereas the water movement in Rubicon Sandy Loam is found to be very slow. In studies of intermittent infiltration and redistribution sequences in a sand and Rubicon Sandy Loam, the Mualem-Dagan model of capillary hysteresis is found to be quite satisfactory with regard to the evaluation of primary and other higher order scanning curves. This prompts one to use further the Mualem and Dagan (1975) model for the problems of rapid intermittent flow situations.

\section{Acknowledgements}

The computations were carried out on CDC computers at the School of Civil Engineering, University of New South Wales, Sydney. The author is thankful to Prof. C L Singh, for his cooperation and help.

\section{List of symbols}

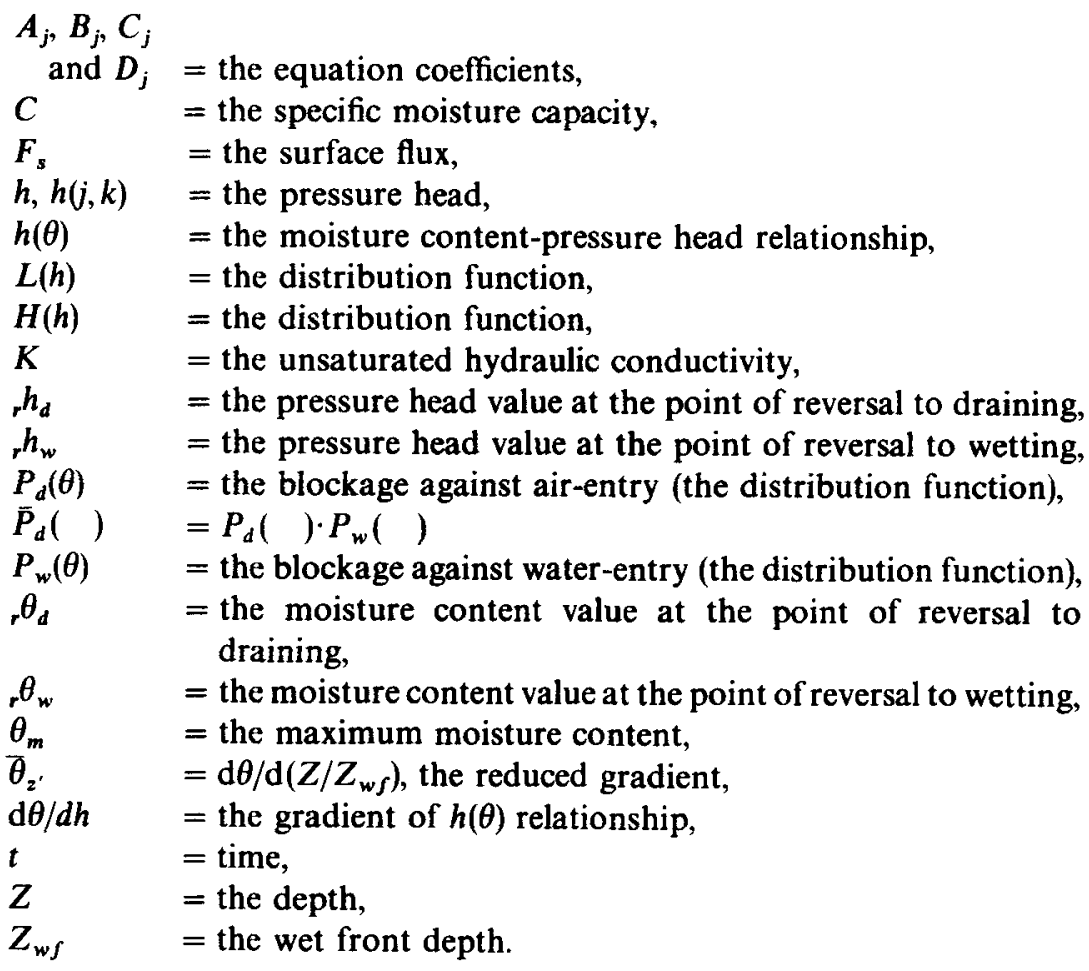

\section{References}

Childs E C 1960 An introduction to the physical basis of water phenomenon (London: Wiley-Interscience) pp. 97-152

Everett D H 1967 Adsorption hysteresis in solid gas interface (ed.) E A Flood (New York: Marcel Dekker) Vol. 2, pp. 1055-1113 
Lees S J and Watson K K 1975 Water Resour, Res. 11943

Mualem Y 1974 Water Resour. Res. 10514

Mualem Y 1977 Water Resour. Res. 13773

Mualem Y and Dagan G 1975 Water Resour. Res. 11452

Parlange J Y 1976 Water Resour. Res. 12224

Perrens S J and Watson K K 1977 Water Resour. Res. 13781

Poulovassilis A and Childs E C 1971 Soil Sci. 112301

Topp G C 1969 Soil. Sci. Soc. Am. Proc. 33645

Topp G C 1971 Soil Sci. Soc. Am. Proc. 35219

Watson K K and Perrens S J 1973 Numerical analysis of intermittent infiltration redistribution, Hydrology Symposium, Inst. Eng. Australia, Perth, Western Australia

Whisler F D and Watson K K 1968 J. Hydrol. 6277 